\title{
O ENSINO DE LÍNGUA PoRTUGUESA NA EDUCAÇÃO BÁSICA: A FORMAÇÃO DE PROFESSORES NO CENTRO DO DEBATE
}

\section{Maria Lucia Marcondes Carvalho Vasconcelos*}

Resumo: O presente artigo pretende discorrer sobre a formação inicial do professor da educação básica, levada a efeito nos cursos de licenciatura do ensino superior, partindo do pressuposto de que, dentre as (muitas) ações possíveis e necessárias para o incremento da qualidade da educação básica, uma delas será, necessariamente, a melhoria da qualidade do ensino que se oferece nos diversos cursos formadores de professores das instituições de ensino superior (IES) do país.

Palavras-chave: Formação inicial de professores. Educação básica. Ensino superior.

\section{INTRODUÇÃo}

$\boldsymbol{Q}$ uando nossas preocupações se voltam para a qualidade do ensino na escola de educação básica brasileira, muitas são as dúvidas e variadas as possibilidades, vislumbradas como caminhos, para a minimização do problema (que é real!).

Neste artigo, pretendemos discorrer a respeito da formação inicial do professor da educação básica, levada a efeito nos cursos de licenciatura do ensino superior, partindo do pressuposto de que, dentre as (muitas) ações possíveis e necessárias para o incremento da qualidade da educação básica, uma delas será, necessariamente, a melhoria da qualidade do ensino que se oferece nos diversos cursos formadores de professores das instituições de ensino superior (IES) do país.

Como marco inicial da presente discussão, pretendemos deixar explicitado nosso posicionamento quanto à figura do professor, seu papel e sua importância. 
O processo de ensino-aprendizagem se dá em sala de aula, envolvendo dois atores principais: aluno e professor. Ambos são imprescindiveis ao processo de educação formal (mesmo quando este ocorre a distância) e desempenham papéis complementares, voltados para os mesmos objetivos.

Ainda que sejam complementares, os papéis de docentes e discentes são distintos. Cada um, do seu lugar, encara e vive o processo de ensino-aprendizagem na busca, em última análise, da aprendizagem, com desempenhos, porém, distintos, definidores de seu próprio papel.

Nesse processo, cabe ao professor o dever de zelar pelo bom andamento de todas as ações que se constituem no que conhecemos como aula. Desde o planejamento anual de um curso, aos planos diários de ensino, passando pela escolha das teorias, métodos, estratégias de ensino e de avaliação, cabe ao professor a responsabilidade - que é sua - de ensinar. Outras responsabilidades serão cobradas dos alunos, mas, como parceiros, estarão ambos - docente e discente - assumindo seus deveres.

Sabemos, porém, que variam muito, de escola para escola, as condições de trabalho oferecidas ao docente em exercício e as características do grupo de alunos em cada uma dessas instituições.

Não há como ignorar que determinados fatores influem diretamente no trabalho de sala de aula: a existência de normas institucionais claramente definidas e cotidianamente cumpridas; a presença ativa da direção e da coordenação pedagógica; o número adequado de alunos por turma; o envolvimento (ou não) das famílias no processo; a existência de material didático-pedagógico em qualidade e quantidade necessárias e outros mais. O professor deverá saber lidar com a somatória de todas essas especificidades.

Escolas diferentes oferecem condições de trabalho igualmente distintas a seus professores, e serão obtidos, em decorrência, resultados desiguais. O que queremos desde já deixar claro é que, na presente análise, professores não serão vistos como os vilões da crise de qualidade vivida por nossa escola, mas também não serão, isoladamente, os heróis que a tudo resolverão.

Professores são parte do problema, portanto, seguramente, qualquer solução possivel deverá passar por eles. Assim, tendo esclarecido qual é o nosso olhar para o professor em exercício, passemos ao nosso pressuposto fundamental: não há como discutir a qualidade da educação básica sem olhar para o que se tem feito no ensino superior.

\section{A discussão sobre a gualidade da EdUCAÇÃo básica Passa, NECESSARIAMENTE, PELO ENSINO SUPERIOR}

O Censo Escolar da Educação Básica de 2013 informa que há 2.095.013 de professores atuando na educação básica brasileira (BRASIL, 2014). Se tomarmos apenas o ensino fundamental I, teremos que $75 \%$ dos docentes cursaram o ensino superior. Se formos ao ensino fundamental II, os docentes formados em nível superior alcançarão 90,4\%. Já no ensino médio, teremos uma porcentagem de $95,4 \%$ de professores formados pelas IES do país.

É sempre bom reafirmar que tal exigência - a de que o professor da educação básica seja formado pelos cursos superiores de licenciatura - está exposta na Lei de Diretrizes e Bases (LDB), n. 9.394/96, em seu artigo 62, que afirma que 
os docentes, para que possam atuar na educação básica, serão formados em nivel superior, em cursos de licenciatura, de graduação plena, sendo "[...] admitida, como formação mínima para o exercício do magistério na educação infantil e nas quatro primeiras séries do ensino fundamental, a oferecida em nivel médio, na modalidade Normal" (BRASIL, 1996).

A formação inicial dos docentes da educação básica vem, portanto, sendo feita pelo ensino superior, como preconizado pela legislação e desejado pela sociedade. Assim, se não houver um olhar mais criterioso para os cursos formadores de professores, continuaremos a não enfrentar um problema, hoje crucial, que é o da formação, muitas vezes, precária desse profissional.

As licenciaturas são responsáveis pela formação inicial dos professores para a educação básica. Dessa forma, caso não haja uma melhoria significativa nesse processo inicial, continuaremos a assistir ao interminável processo de compensação, desempenhado pelas ações de formação continuada que o poder público -seja ele municipal, estadual ou federal - tem que disponibilizar ao corpo de docentes de suas redes. Tal esforço, bastante dispendioso, busca suprir as lacunas deixadas pelos cursos de formação inicial.

A título de exemplificação, trazemos os números relativos a cursos ofertados pela Prefeitura Municipal de São Paulo aos professores de sua rede de ensino. Tomamos o período de 2001 a 2010 como exemplo, apresentando o número de professores que frequentaram, em cada ano, os diversos cursos oferecidos:

Tabela 1 - Número de professores da Rede Municipal de Ensino de São Paulo que frequentaram cursos de capacitação oferecidos pela Diretoria de Orientação Técnica (DOT). Período: de 2001 a 2010.

\begin{tabular}{|c|c|c|c|c|c|c|c|c|c|}
\hline 2001 & 2002 & 2003 & 2004 & 2005 & 2006 & 2007 & 2008 & 2009 & 2010 \\
\hline $\begin{array}{l}3.57 \\
7\end{array}$ & $\begin{array}{l}11.36 \\
4\end{array}$ & $\begin{array}{l}20.68 \\
6\end{array}$ & $\begin{array}{l}26.26 \\
3\end{array}$ & $\begin{array}{l}12.45 \\
7\end{array}$ & $\begin{array}{l}18.55 \\
1\end{array}$ & $\begin{array}{l}14.02 \\
6\end{array}$ & $\begin{array}{l}29.36 \\
1\end{array}$ & $\begin{array}{l}19.99 \\
1\end{array}$ & $\begin{array}{l}30.35 \\
9\end{array}$ \\
\hline & & & & & & & & Total: & 186.635 \\
\hline
\end{tabular}

As redes de ensino, impulsionadas não só pela voz da sociedade, que começa a se conscientizar do direito à qualidade do ensino, mas também pela rapidez dos avanços tecnológicos e pela disseminação em tempo real dos conhecimentos, abrem espaço para que equipes de profissionais especializados se debrucem sobre as inúmeras possibilidades que se apresentam no âmbito da educação continuada (ou permanente). No entanto, é preciso ressaltar que existe uma clara diferença entre os programas de capacitação docente que se voltem para a atualização de conhecimentos e/ou reflexão sobre a prática docente e aqueles que visam suprir as deficiências de um processo inicial de formação precário.

Se os primeiros, voltados para a atualização e/ou reflexão, cumprem um papel indispensável na sociedade do conhecimento na qual vivemos, os outros estarão refazendo um mesmo percurso, inicialmente mal feito. Desperdiçaram-se, portanto, tempo, esforços e recursos financeiros num processo que não cumpriu seu principal objetivo: o de, adequadamente, formar professores para o exercício do magistério na educação básica. 
O artigo 61 da LDB, em seu parágrafo único, trata da formação desses profissionais e já aponta, com clareza, o necessário relacionamento entre o processo acadêmico de formação inicial (teórico) e sua prática futura:

Parágrafo único. A formação dos profissionais da educação, de modo a atender às especificidades do exercício de suas atividades, bem como aos objetivos das diferentes etapas e modalidades da educação básica, terá como fundamentos: I - a presença de sólida formação básica, que propicie o conhecimento dos fundamentos científicos e sociais de suas competências de trabalho;

II - a associação entre teorias e práticas, mediante estágios supervisionados $e$ capacitação em serviço;

III - o aproveitamento da formação e experiências anteriores, em instituições de ensino e em outras atividades (BRASIL, 1996).

Além da LDB, outros documentos legais versam sobre a formação inicial de professores para a educação básica, como o Parecer CNE/CP n. 09/2001 (BRASIL, 2001), que apresenta as Diretrizes Curriculares Nacionais para a Formação de Professores da Educação Básica, em nível superior, curso de licenciatura, de graduação plena, ou a Resolução CNE/CP n. 01/2006, que institui as Diretrizes Curriculares Nacionais para o Curso de Graduação em Pedagogia, licenciatura (BRASIL, 2006).

A Deliberação CEE n. 111/2012, do Conselho Estatual de Educação de São Paulo, fixa, para os estabelecimentos de ensino superior vinculados ao sistema estadual de ensino, as Diretrizes Curriculares Complementares para a Formação de Docentes para a Educação Básica, nos Cursos de Graduação de Pedagogia, Normal Superior e Licenciaturas (BRASIL, 2012). Essa deliberação abarca toda a educação básica, em todas as suas modalidades, desde a educação infantil até o ensino médio, e, basicamente, o ponto diferencial a ser destacado é aquele a que se refere o seu artigo $5^{\circ}$, em que fica demonstrada a preocupação daquele Conselho com a formação de professores, a qual não pode perder de vista a futura atuação desses profissionais em salas de aula da educação básica:

Art. $5^{\circ}$ - A formação científico-cultural tem por objetivo ampliar a formação obtida no ensino médio e aprofundar os conteúdos a serem ensinados na pré-escola e anos iniciais do ensino fundamental e incluirá na estrutura curricular:

I - estudos da Língua Portuguesa falada e escrita, da leitura, produção e utilização de diferentes gêneros de textos, indispensáveis para o trabalho em sala de aula e para o registro e comunicação de sua experiência docente;

II - estudos de Matemática necessários tanto para as atividades de ensino como para o uso e produção de indicadores e estatísticas educacionais;

III- estudos de História sobre a constituição das grandes divisões sócio-politicas tanto do Brasil como do mundo globalizado;

IV - estudos de Ciências Naturais incluindo a compreensão da evolução da vida, do corpo humano e seu crescimento, da saúde e da doença;

VI- utilização das Tecnologias da Comunicação e Informação (TICs) como recurso pedagógico e ferramenta para o próprio desenvolvimento intelectual e profissional;

VII - ampliação e enriquecimento da cultura geral incluindo experiências curricu- 
lares diversificadas que propiciem acesso, conhecimento e familiaridade com instituições e manifestações culturais, artísticas e científicas (BRASIL, 2012, p. 1-2).

Vemos, portanto, que os documentos legais se preocupam com a necessária interação entre ensino superior - locus de formação de futuros professores - e a educação básica - locus de seu futuro exercício profissional. Na prática, entretanto, o que se vê é um grande distanciamento entre esses dois niveis de ensino.

Ao discutir as licenciaturas ${ }^{1}$, Paiva (2005) afirma serem poucos os docentes que se preocupam e se envolvem com os aspectos da formação docente, comportando-se como se fossem professores de bacharelado. As questões de ensino-aprendizagem, voltadas para a docência na educação básica, não fazem parte nem de suas preocupações nem de seus planos de ensino, e os egressos desses cursos, quando formados, não sabem como transpor, didaticamente, os conhecimentos adquiridos em seus cursos superiores. Curiosamente, muitos desses docentes nunca foram professores da educação básica, desconhecendo, portanto, a realidade das escolas para as quais formam professores.

As questões aqui levantadas abrem espaço para uma outra questão que se refere à necessidade - cada vez mais premente - de investimento na educação continuada dos docentes da educação básica, que deve, no entanto, ser planejada com alguns cuidados.

Toda proposta voltada para a educação continuada de professores deve, além de prever diversas soluções que venham a atender às necessidades e expectativas desse público específico, levar em conta as experiências prévias desses profissionais. Há, portanto, a necessidade de se trabalhar com programas interativos, nos quais os participantes possam integrar estratégias dinâmicas de ensino-aprendizagem, como discussões em grupo, estudos e discussões de casos, exercícios de simulação, aprendizagem baseada na resolução de problemas e análise dos possiveis cenários a serem vivenciados na prática.

Alerte-se, no entanto, para o fato de que se basear apenas e tão somente nas experiências prévias trazidas pelo grupo pode se constituir em perigosa armadilha, facultando a disseminação e a cristalização de práticas não tão produtivas e/ou inovadoras, como podem avaliar alguns professores. Nem toda experiência pode ser classificada como positiva. Algumas experiências podem ser, até mesmo, deseducativas.

Mizukami (2004, p. 305), referindo-se às análises apresentadas por Kunzman (2003) relativas a processos formais de preparação de professores experientes, afirma que as complexidades do ato de ensinar exigem "[...] uma preparação mais aprofundada, uma dialética entre teoria e prática que a escola sozinha não pode oferecer [...]". Não se trata de diminuir a importância da prática, da experiência, mas sim de dar um passo à frente, situando o espaço da educação continuada "[...] ]em um contexto intelectualmente rigoroso de reflexão, feedback e colaboração".

Outro dado a ser atentamente observado é o da adequação dos cursos/programas ofertados às reais necessidades e interesses daqueles que os frequentarão. É uma constante a queixa de que os órgãos centrais das diferentes secretarias de educação - sejam elas municipais ou estaduais - nem sempre costumam

1 Paiva discute, especificamente, as licenciaturas em Letras, mas sua análise cabe, perfeitamente, às demais licenciaturas. 
ouvir previamente suas redes, oferecendo cursos que redundam em atividades já dominadas, deixando de lado fragilidades que deveriam ser enfrentadas.

São os cursos de licenciatura, porém, os responsáveis pela formação inicial de professores para a educação básica, e neles devem ser propiciadas situações concretas para que o futuro professor comece a desenhar, criticamente, seu perfil profissional.

Segundo Mizukami (2004, p. 291), além da preocupação com o domínio do conteúdo específico da disciplina na qual o professor está sendo formado, deverá ter, a IES, uma clara preocupação com o "conhecimento de conteúdo pedagógico", que

[...] é construído constantemente pelo professor ao ensinar a matéria e que é enriquecido e melhorado quando se amalgamam os outros tipos de conhecimento explicitados na base. Inclui compreensão do que significa ensinar um tópico de uma disciplina específica, assim como os princípios e técnicas que são necessários para tal ensino [...].

Devemos salientar, no entanto, que os estágios curriculares supervisionados obrigatórios constituem-se - ou deveriam se constituir - em momento privilegiado na formação de professores. A legislação que rege a matéria, Resolução CNE/ CP 02/2002, determina a carga horária dos cursos de formação docente, estabelecendo para eles um mínimo de 2.800 (duas mil e oitocentas) horas.

Essa carga horária deverá estar assim distribuída:

- 400 (quatrocentas) horas de prática como componente curricular, vivenciadas ao longo do curso;

- 400 (quatrocentas) horas de estágio curricular supervisionado a partir do início da segunda metade do curso;

- 1.800 (mil e oitocentas) horas de aulas para os conteúdos curriculares de natureza científico-cultural;

- 200 (duzentas horas) para outras formas de atividades acadêmico-científico-culturais (BRASIL, 2002b, p. 1).

A mesma Resolução CNE/CP 01/2002, em seu artigo 13, determina que o estágio deva realizar-se

[...] em escola de educação básica e, respeitando o regime de colaboração entre os sistemas de ensino, deve ser desenvolvido a partir do início da segunda metade do curso e ser avaliado conjuntamente pela escola formadora e a escola campo de estágio (BRASIL, 2002a, p. 6)

Aqui está a maior fragilidade dos cursos de licenciatura: o pouco aproveitamento que se consegue tirar das ações da prática, oportunizadas pelo estágio curricular supervisionado.

As ações conjuntas, previstas pela regulamentação, não se concretizam na prática. As IES pouco (ou nada) dialogam com as instituições campo de estágios e, quando o fazem, muito raramente o diálogo se estabelece com os professores, mas sim em nivel das instâncias administrativas.

O estagiário passa, assim, num processo absolutamente aleatório, por uma série de experiências de caráter bastante variado. Tais experiências vão do mais gratificante êxito - quando boas aulas são observadas e oportunidades de regên- 
cia supervisionada ocorrem - ao mais retumbante fracasso - quando aulas precárias são assistidas e professores rejeitam, com indiferença e até descaso, a presença do estagiário em suas aulas.

O momento dos estágios curriculares, portanto - quase sempre supervisionados a distância -, que deveria ser um espaço privilegiado da prática na formação de futuros professores, acaba por se transformar em um verdadeiro martírio diante de tantas dificuldades e obstáculos impostos ao aluno da licenciatura.

O estagiário, se realmente supervisionado, tanto pela instituição formadora como por aquela que o recebe, será sempre um elemento positivo, que somará esforços no sentido de auxiliar, ativamente, o professor que o recebe. É preciso, no entanto, integrá-lo ao processo, não apenas favorecendo o seu aprendizado, mas utilizando seu potencial para tarefas - insistimos - supervisionadas, que colaborarão com o trabalho do professor da escola campo de estágio.

Certamente, alguns entraves dificultam o processo e devem ser removidos. $\mathrm{O}$ primeiro deles refere-se à dificuldade de compreensão da importância do estágio, desvalorizado tanto nas licenciaturas (no bojo da desvalorização das disciplinas pedagógicas) quanto no âmbito das escolas de educação básica, que não se veem como parceiras nesse processo.

Por outro lado, não é incomum haver, nas IES, professores supervisores sem experiência docente na área e/ou na educação básica. Esses professores acabam por se envolver com a, geralmente, excessiva burocracia do estágio (fichas e relatórios), que assumem importância desproporcional.

A ausência de diálogo entre as instituições envolvidas - a IES e a escola de educação básica - faz com que as instituições receptoras relutem em receber os estagiários, dificultando, assim, o cumprimento de uma carga horária que não é pequena.

Uma experiência exitosa que poderia nortear mudanças nessa relação é o Programa Institucional de Bolsa de Iniciação à Docência (Pibid), instituído pela Coordenadoria de Aperfeiçoamento de Pessoal de Ensino Superior (Capes ${ }^{2}$ ) com o objetivo de aperfeiçoar e valorizar a formação de professores para a educação básica.

O Programa concede bolsas a alunos de licenciatura participantes de projetos de iniciação à docência, desenvolvidos por IES, em parceria com escolas de educação básica da rede pública de ensino. Os projetos em questão devem promover a inserção dos estudantes no contexto das escolas públicas desde o início da sua formação acadêmica, para que desenvolvam atividades didático-pedagógicas sob a orientação de um docente da licenciatura e de um professor da escola.

Nos mesmos moldes do Pibid, os estágios curriculares supervisionados poderiam se desenvolver, desde que a parceria prevista na Resolução CNE/ CP n. 01/2002 se concretizasse efetivamente (BRASIL, 2002a). Aproximar a licenciatura da escola de educação básica é ação prioritária para que ganhos na qualidade de ambos os niveis de ensino venham a ocorrer.

Teaching Portuguese at basic education: teacher training at the center of debate

Abstract: This article intends to discuss the initial training of teachers of basic

2 Órgão do Ministério da Educação (MEC) responsável pela formulação das políticas de pós-graduação. 
education, a preparation which is carried out in higher education degree courses, based on the assumption that, among (many) possible and necessary actions to increase the quality of basic education, one of them will necessarily be to improve the quality of instruction that is offered in the several teacher education programs in undergraduate courses in the country.

Keywords: Initial training of teachers. Basic education. Undergraduate education.

\section{REFERÊNCIAS}

BRASIL. Lei n. 9.394, de 20 de dezembro de 1996. Estabelece as diretrizes e bases da educação nacional. Disponivel em: <http://www.planalto.gov.br/ccivil_03/leis/L9394.htm>. Acesso em: 23 jan. 2017.

BRASIL. Ministério da Educação. Conselho Nacional de Educação. Parecer CNE/CP n. 09/2001, de 8 de maio de 2001. Diretrizes Curriculares Nacionais para a Formação de Professores da Educação Básica, em nivel superior, curso de licenciatura, de graduação plena. Disponivel em: <http://portal.mec.gov.br/ cne/arquivos/pdf/009.pdf>. Acesso em: 23 jan. 2017.

BRASIL. Conselho Nacional de Educação. Resolução CNE/CP 01/2002, de 18 de fevereiro de 2002a. Institui Diretrizes Curriculares Nacionais para a Formação de Professores da Educação Básica, em nivel superior, curso de licenciatura, de graduação plena. Disponível em: <http://portal.mec.gov.br/cne/arquivos/pdf/rcp01_02.pdf>. Acesso em: 23 jan. 2017.

BRASIL. Conselho Nacional de Educação. Resolução CNE/CP 02/2002b, de 19 de fevereiro de 2002. Institui a duração e a carga horária dos cursos de licenciatura, de graduação plena, de formação de professores da Educação Básica em nível superior. Disponível em: <http://portal.mec.gov.br/cne/arquivos/ pdf/CP022002.pdf>. Acesso em: 23 jan. 2017.

BRASIL. Conselho Nacional de Educação. Resolução CNE/CP 01/2006. Institui Diretrizes Curriculares Nacionais para o Curso de Graduação em Pedagogia, licenciatura. Disponivel em: <http://portal.mec.gov.br/cne/arquivos/pdf/ rcp01_06.pdf>. Acesso em: 23 jan. 2017.

BRASIL. Conselho Estadual de Educação. Deliberação CEE n. 111/2012. Fixa Diretrizes Curriculares Complementares para a Formação de Docentes para a Educação Básica nos Cursos de Graduação de Pedagogia, Normal Superior e Licenciaturas, oferecidos pelos estabelecimentos de ensino superior vinculados ao sistema estadual. Disponivel em: <file://C:/Users/114195/Downloads/ deliberacao_cee_111_12.pdf>. Acesso em: 23 jan. 2017.

BRASIL. Instituto Nacional de Estudos e Pesquisas Anísio Teixeira. Censo escolar da educação básica 2013. Brasília: Inep, 2014. Disponivel em: <http://download.inep.gov.br/educacao_basica/censo_escolar/resumos_tecnicos/resumo_tecnico_censo_educacao_basica_2013.pdf>. Acesso em: 23 jan. 2017.

MIZUKAMI, M. da G. N. Relações universidade-escola e aprendizagem da docência: algumas lições de parcerias colaborativas. In: BARBOSA, R. L. L. (Org.). Trajetórias e perspectivas da formação de educadores. São Paulo: Unesp, 2004. p. 285-314. 
PAIVA, V. L. M. O. O novo perfil dos cursos de licenciatura em Letras. In: TOMICH, V. L. et al. (Org.). A interculturalidade no ensino de inglês. Florianópolis: Editora da UFSC, 2005. p. 345-363.

Recebido em julho de 2016. Aprovado em novembro de 2016. 